Francis Bonnet MD, * Jean Paul Derosier MD, $\dagger$ Frederic Pluskwa MD, * Kou Abhay MD, * A. Gaillard MD†

\title{
Cervical epidural anaesthesia for carotid artery surgery
}

A series of 394 patients (25I men, 143 women; mean age $70.0 \pm$ $8.4 \mathrm{yr}$ ) selected for carotid artery surgery (CAS) performed under cervical epidural anaesthesia (CEA) was analysed retrospectively. Carotid endarterectomy was performed in 326 patients and saphenous vein bypass in 68 . The cervical epidural administration of $15 \mathrm{ml} 0.5$ per cent bupivacaine or $0.37-0.40$ per cent bupivacaine plus fentanyl $(50-100 \mu \mathrm{g})$ resulted in an effective sensory blockade from $C_{2}$ to $T_{4}-T_{8}$. Patients were maintained awake during the surgical procedure in comfortable condition. Serious complications included dural puncture in two patients, epidural venipuncture in six patients and respiratory muscle paralysis in three patients. Hypotension (10.9 per cent) and bradycardia (2.8 per cent) were the most frequent sideeffects of CEA. Transient neurological events were noticed in 84 patients during the surgical procedure. A definite neurological deficit occurred postoperatively in 12 patients. Three patients suffered postoperative myocardial infarction. The mortality rate was 2.3 per cent (nine patients). Carotid artery surgery may be performed under CEA but haemodynamic variables should be monitored closely and managed closely during the procedure.

Une étude rétrospective a été effectuée sur une série de 394 patients (251 hommes, 143 femmes, d'âge moyen $70.0 \pm 8.4$ ans) opérés de la carotide sous anesthésie péridurale cervicale. Trois cent vingt six patients ont subi une endartériectomie carotidienne et 68 un pontage carotidien. L'anesthésie péridurale a été effectuée avec de la bupivacaine à 0.5 pour cent (49 patients) puis $0,37-0,40$ pour cent (345 patients) $(15 \mathrm{ml})$ associée à du fentanyl (50-100 $\mu \mathrm{g}$ ). Un bloc sensitif étendu de

\section{Key words}

ANAESTHESIA: vascular;

ANAESTHETIC TECHNIQUES: epidural, cervical;

ANAESTHETICS, LOCAL: bupivacaine;

BRAIN: blood flow;

SURGERY: carotid artery surgery.

From the Departement d'Anesthésie,* Hopital Henri Mondor, Creteil and the Service d'Anesthésie, † Clinique Poirier, Chambery.

Address correspondence to: Dr. F. Bonnet, Departement d'Anesthésie, 51, avenue du marechal de Lattre de Tassigny, 94000 Creteil, France.
$C_{2}$ à $D_{4}-D_{8}$ a ainsi été obtenu. Les parients sont restés éveillés pendant la durée de l'acte opératoire dans des conditions de confort acceptables. Les complications sérieuses rencontrées ont été la survenue d'une brèche duremérienne dans deux cas, d'une brèche vasculaire dans six cas et d'une insuffisance respiratoire chez trois patients. Hypotension (10,9 pour cent et bradycardie (2,8 pour cent) étaient les effets secondaires les plus fréquemment observés. Un accident neurologique transitoire s'est produit chez 84 patients pendant l'intervention chirugicale. Un accident neurologique irréversible est survenu chez 12 patients. Trois infarctus du myocarde ont été diagnostiqués dans les suites opératoires. La mortalité de cetre série était de 2,3 pour cent. L'anesthésie péridurale cervicale apparaît comme une alternative possible pour la chirurgie carotidienne qui réclame de toutes façons une surveillance hémodynamique serrée.

Carotid artery surgery (CAS) is one of the most common vascular surgical procedures. It is performed under either general or regional anaesthesia. ${ }^{1,2}$ Regional anaesthesia allows simple and reliable monitoring of cerebral function during the procedure by means of verbal communication with the patient and frequent evaluation of motor strength. ${ }^{1,2}$ Two different techniques can be used for regional anaesthesia of the neck: cervical block or cervical epidural anaesthesia (CEA). Deep cervical block requires identification of the second, third and sometimes the fourth cervical nerve roots on the same side as the surgical field. Moreover, a superficial block must be performed because of frequent cutaneous sensory anastomoses with some branches of the lower cervical plexus and of the trigeminal nerve. Though appealingly simple the cervical block has a failure rate of nearly 20 per cent when performed by the classical approach ${ }^{3}$ Anatomical difficulties may be encountered especially in obese patients with a short neck.

Cervical epidural anaesthesia (CEA), first described by Dogliotti in $1933^{4}$ for thoracic surgery, is used mainly for relief of chronic pain in the head and neck or cancer pain due to Pancoast syndrome. ${ }^{5}$ In only one previous report has CEA been described as an anaesthetic technique suitable for $\mathrm{CAS} .{ }^{6}$ In our institution we chose regional anaesthesia for CAS and selected CEA because of the 
familiarity of our anaesthetic team with this technique for chronic pain relief. In the present study we report four years' experience of CEA and discuss its advantages and drawbacks.

\section{Methods}

\section{Patients}

From 1984 to 1988,394 consecutive patients submitted to CAS in our institution were operated upon with CEA after they had given their informed consent and were included in this study retrospectively. Non-cooperative patients and patients who received heparin before surgery were excluded from receiving CEA. Antihypertensive drugs, betablocking adrenergic agents and calcium channel blockers were continued until the morning of the operation. Flunitrazepam, $1 \mathrm{mg}$, was given orally as premedication two hours before surgery.

\section{Anaesthetic technique}

Patients were placed in the sitting position with the head flexed and resting on the thorax, in order to open the lowest cervical interspaces. The spinous process of $C_{7}$, which is horizontal in this position, was easily identified. An 18-gauge Tuohy needle was inserted by a midline approach into the $\mathrm{C}_{6}-\mathrm{C}_{7}$ or $\mathrm{C}_{7}-\mathrm{T}_{1}$ interspace after cutaneous local anaesthesia. The epidural space was identified by aspiration of a saline solution drop hanging at the needle base. Careful aspiration ensured that the needle had not entered the subarachnoid space nor penetrated an epidural vein, and an epidural catheter was inserted gently. In ASA physical status IV patients, CEA was performed in the lateral decubitus position, using the loss of resistance technique. In both cases, patients were then placed in the supine or Trendelenberg position and the local anaesthetic solution was injected after a test dose of $2 \mathrm{ml}$ of 2 per cent lidocaine. The solution consisted of $15 \mathrm{ml}, 0.5$ per cent bupivacaine in the first 49 patients and then of $15 \mathrm{ml}, 0.37-0.40$ per cent solution of the same local anaesthetic in the remainder. Fentanyl 50 to $100 \mu \mathrm{g}$ was administered into the epidural space together with bupivacaine in 303 patients to improve analgesia. Arterial $\mathrm{PCO}_{2}$ was measured before and $30 \mathrm{~min}$ after epidural anaesthesia in the first 50 patients who received bupivacaine-fentanyl solution. Sensory blockade was evaluated by pin-prick. After cutaneous incision and dissection, the carotid sheath was opened after infiltration with lidocaine. When CAS included a vein bypass graft, the saphenous vein was removed under local anaesthesia.

\section{Monitoring}

Routinely, monitoring included electrocardiogram (lead CM5) and arterial blood pressure measured by a sphyg- momanometer (dynamap ${ }^{\circledR}$ ) or via a radial artery catheter. Patients were carefully observed for changes in cerebral function as evidenced by loss of consciousness, somnolence, and neurological deficit of the hand and the arm. Ephedrine 3 to $6 \mathrm{mg}$ was injected IV when systolic arterial pressure decreased more than 30 per cent of the preanaesthetic value or to less than $95 \mathrm{mmHg}$ or when neurological symptoms developed during carotid artery clamping, associated with a decrease in blood pressure. Decreases in heart rate to less than 45 beats $\mathrm{min}^{-1}$ were treated with IV atropine. Heparin, 50 to $70 \mathrm{u} \cdot \mathrm{kg}^{-1}$, was IV injected before carotid artery clamping.

\section{Postoperative care}

Blood pressure and heart rate were monitored every five minutes with a sphygmomanometer or continuously with a radial artery catheter, during the first 24 hr postoperatively. Acute hypertension was treated with calcium channel blockers $(10 \mathrm{mg}$, sublingual nifedipine or $1 \mu \mathrm{g}$. $\mathrm{kg}^{-1} \cdot \mathrm{h}^{-1}$ IV nicardipine) and hypotension with ephedrine in IV boli or continuous infusion. The epidural catheter was withdrawn in the recovery room when activated coagulation time was normal. Electrocardiogram and myocardial enzymes were obtained during the three first postoperative days and at the end of the hospital stay. Postoperative myocardial infarction was defined by new $\mathrm{Q}$ waves on the ECG and an increase in CK-MB greater than $50 \mathrm{E}^{-3}$ iu $\mathrm{ml}^{-1}$.

\section{Statistics}

Mean values of arterial $\mathrm{PCO}_{2}$ were compared using ANOVA and paired Student's $t$ test.

\section{Results}

The patient demographics are reported in Table I. Carotid endarterectomy was performed in 326 patients and saphenous vein bypass graft in 68 .

\section{TABLE I Patients' demographics}

$\begin{array}{lc}\text { Sex ratio: } 251 \text { men; } 143 \text { women } \\ \text { Mean age: } 70.0 \pm 8.4 \text { yr } & \\ \text { Hypertension:* } & 268(68 \%) \\ \text { Documented ischemic cardiopathy: } \dagger & 169(43 \%) \\ \text { Previous myocardial infarction: } & 53(13.5 \%) \\ \text { Neurological symptoms: } & 286(72.5 \%) \\ \text { Transient ischaemic attacks: } & 156(39.5 \%) \\ \text { Previous stroke: } & 41(10.5 \%) \\ \text { Vertebral insufficiency } & 114(29 \%)\end{array}$

*Includes patients treated for hypertension or with a systolic blood pressure $>180 \mathrm{mmHg}$ and/or a diastolic blood pressure $>100 \mathrm{mmHg}$. tDocumented by typical chest pain, ECG and/or thallium scintigraphy or coronary angiography. 


\section{Effectiveness of anaesthesia}

Within $30 \mathrm{~min}$ of epidural injection, sensory blockade extended from $C_{2}$ to $T_{4}-T_{8}$. One hundred eighty-five patients felt comfortable during the surgical procedure and did not require additional analgesia. Two hundred and nine patients received small titrated doses of IV benzodiazepines (diazepam: $2-10 \mathrm{mg}$, flunitrazepam:0.2-I $\mathrm{mg}$ ) or narcotics (fentanyl: $25-50 \mu \mathrm{g}$ ) but verbal communication was always maintained. No patient required additional epidural injections.

\section{Unwarranted effects}

The identification of the epidural space was successful in 386 patients. Epidural venipuncture occured in six patients (Table II); in five of these the puncture was identified definitively by blood aspiration, the catheter was re-inserted in the superior adjacent spinal interspace and heparin was proscribed for surgery. In one patient, seizures were noticed after injection through the epidural catheter demonstrating the epidural venipuncture; seizures were controlled after thiopentone IV injection and surgery was performed under general anaesthesia. Postoperatively the patient had no neurological deficit. Penetration of the dura was noted in two instances and these two patients were operated upon with general anaesthesia (Table II).

Three patients with chronic obstructive pulmonary disease (COPD) developed progressive respiratory embarrassment within 20 min of the epidural injection of 0.5 per cent bupivacaine and they were managed with controlled pulmonary ventilation after induction of general anaesthesia (Table II). Arterial $\mathrm{PCO}_{2}$ increased from $37.3 \pm 3.4$ to $40.2 \pm 3.3 \mathrm{mmHg}(P<0.05)$ when it was measured in patients who received the fentanylbupivacaine combination.

Transient or recurrent hypotension, as defined above, was noticed in 43 ( 10.9 per cent) (lowest systolic blood pressure $90 \mathrm{mmHg}$ ) and bradycardia $<45 \mathrm{~min}^{-1}$ in 11 patients ( 2.8 per cent) (lowest value $40 \mathrm{~b} \cdot \mathrm{min}^{-1}$ ) (Table II). This was treated promptly with IV ephedrine. In the other patients, the decrease in blood pressure and heart rate, if any, was less than 20 per cent of control values. Minor side-effects as nasal congestion and hoarseness were observed in 10.5 per cent of the patients.

\section{Neurological outcome and complications of surgery}

Transient alteration in consciousness and/or motor deficit of the right arm were noticed in 84 patients ( 21.3 per cent) during the surgical procedure. In two patients a transient decreased level of consciousness was observed during carotid dissection. In 35 patients, a sudden alteration in consciousness with a loss of verbal communication occurred within two minutes of carotid artery clamping. An arterial shunt was inserted in those patients and allowed continued carotid artery clamping without neurological disturbances in 31 patients. In four patients some alteration in consciousness persisted after shunt insertion and general anaesthesia with tracheal intubation and controlled ventilation was instituted. In 42 patients, alteration in consciousness occurred during carotid clamping. In four of these, the increase in blood pressure induced by ephedrine improved the level of consciousness, in the remaining patients neurological disturbances disappeared after declamping. In addition, transient neurological deficits were noticed within two minutes of carotid declamping in five patients.

The first $24 \mathrm{hr}$ after surgery were complicated by hemiplegia in 12 (three per cent) due to carotid occlusion in seven patients and to cerebral oedema induced by hyperperfusion syndrome in five. Hypotension might be implicated in the occurrence of carotid occlusion in two patients. The five patients who developed a hyperperfusion syndrome had had previously a severe $(>90$ per cent) carotid artery stenosis. In three patients $(0.75$ per cent) a postoperative myocardial infarction was documented on the second postoperative day. The mortality rate of this series was 2.3 per cent (nine patients). Death was related to neurological deficit in six patients, to myocardial infarction in one patient, and to cervical haematoma in two patients.

TABLE II Complications of cervical cpidural anaesthesia

\begin{tabular}{lll}
\hline & Incidence & Management \\
\hline Hypotension (SAP $<95 \mathrm{mmHg})$ & 43 & ephedrinc \\
Bradycardia $\left(\mathrm{HR}<45 \mathrm{~min}^{-1}\right.$ ) & 11 & atropine \\
Venipuncture & 6 & heparin cancelled \\
Seizure & 1 & general anaesthesia \\
Dural puncture & 2 & gencral anaesthesia \\
Respiratory failure & 3 & controlled ventilation \\
\hline
\end{tabular}

SAP: systolic arterial pressure.

HR: heart rate. 


\section{Discussion}

This series of documents that CEA provided adequate anaesthesia for CAS. Nevertheless side effects were observed, the most common being hypotension and bradycardia which require careful monitoring.

\section{Anaesthetic technique}

The technique of CEA appears to be simple and successful in the majority of the patients. The hanging-drop technique, performed in the sitting position, allowed ready identification of the cervical epidural space. At the $C_{6}-C_{7}$ or $\mathrm{C}_{7}-\mathrm{T}_{1}$ level the epidural space measures $3-4 \mathrm{~mm}$ while it becomes narrower in higher segments. ${ }^{7}$ Diffusion of the local anaesthetic solution in the cephalad direction within the skull is precluded by the adhesion of the meningeal dura to the endosteal dura. Diffusion may occur along the spinal roots and at the base of the skull. ${ }^{8}$ This might explain why a large volume of local anaesthetic solution was necessary to obtain an effective blockade, despite the small size of the cervical epidural space compared with the size of the lumbar epidural space. By contrast, the thickness of the dura mater which is $2.5 \mathrm{~mm}$ at the cervical versus $0.5 \mathrm{~mm}$ at the lumbar level ${ }^{9}$ might account for the infrequency of dural puncture. It occurred only twice at the beginning of the series. In a series of 790 consecutive cervical epidural nerve blocks, Waldman reported only two unintentional dural punctures. ${ }^{10}$ To our knowledge, direct spinal trauma has never been reported with this technique, though the proximity of the spinal cord necessitates a cautious approach. Epidural venipuncture occurred in six patients. Since the pressure is especially negative in epidural veins in the sitting position, the venipuncture was documented in these patients only by aspiration through the Tuohy needle. A venipuncture prevents the administration of heparin during the surgical procedure or leads to postponement of surgery if heparin administration is absolutely indicated. In addition, one may be concerned by the risk of epidural haematoma when heparin is given before carotid clamping. We did not observe such an event in this series. Two larger series of 3164 and 950 anticoagulated patients selected for vascular surgery under epidural or spinal anaesthesia, were reported to be free of such complication. ${ }^{11,12}$ Rao and El Etr, " suggested that complications of anticoagulant treatment may be avoided by withdrawing the epidural catheter in the postoperative period, only when heparin activity is minimal.

\section{Consequences of CEA}

\section{RESPIRATORY EFFECTS}

Since the phrenic nerve originates from $C_{3}$ to $C_{5}$, nerve conduction may be impaired by CEA. Extension of the block may also impair intercostal muscle function. In young healthy volunteers no change in resting ventilation was noticed after 1.5 per cent lidocaine cervical epidural administration. ${ }^{13}$ In patients free of previous respiratory dysfunction a mild decrease in tidal volume, minute ventilation associated with a slight increase in $\mathrm{PaCO}_{2}$ have been found.$^{14}$ Epidural fentanyl combined with the local anaesthetic solution depressed ventilation ${ }^{15}$ but the measured increase in $\mathrm{PaCO}_{2}$ was not important in this study. Indeed, the 21 per cent of patients who showed transient neurological deficit during the surgical procedure is comparable to the 18-25 per cent range of patients who have been reported to have had EEG ischaemic abnormalities during carotid clamping under general anaesthesia. ${ }^{16,17}$ Cervical epidural anaesthesia induced respiratory muscle paralysis in the three patients with COPD after they received 0.5 per cent bupivacaine without fentanyl. They demonstrated progressive dyspnoea which required controlled pulmonary ventilation. Inadvertent subdural injection is an alternative explanation for this type of accident. ${ }^{18}$ Since respiratory failure has also been documented after unilateral phrenic nerve block $^{19}$ this risk is not eliminated when a cervical block is performed in patients with compromised respiratory function. ${ }^{20}$ These complications encouraged us to reduce the concentration and the volume of epidurally injected bupivacaine and to postpone patients with severely compromised respiratory function.

\section{CARDIOVASCULAR EFFECTS}

Cardiac sympathetic blockade is induced by CEA and consequently decreases in arterial blood pressure and heart rate are observed. ${ }^{21,22}$ Incomplete impairment in baroreflex sensitivity has also been noticed. ${ }^{21-23}$ Cardiac sympathetic blockade induced by epidural block has been shown to reduce myocardial ischaemia in $\operatorname{dog}^{24}$ and to decrease the incidence of myocardial ischaemia in patients submitted to vascular surgery. ${ }^{25}$ It is suggested that patients with coronary artery disease who arc commonly scheduled for CAS may benefit from CEA. By contrast, too great a decrease in blood pressure may compromise coronary and cerebral perfusion and have to be corrected. In this study, we observed a 0.75 per cent incidence of postoperative myocardial infarction which was slightly less than the 1.4-2.0 per cent reported in recent series ${ }^{26.27}$ and was considerably less than the 10-18.2 per cent incidence reported in high-risk patients operated upon under general anaesthesia. ${ }^{28.29}$

\section{Comparison with cervical block}

Although this was not a comparative study, several observations may be made with the knowledge of the advantages and drawbacks of cervical blocks. Previous 
reported series of patients operated upon with cervical block were not analysed in terms of failures, side-effects or complications of the technique. ${ }^{1,2}$ Nevertheless, complications such as seizures ( 0.9 per cent) or unexpected spinal injection ( 0.9 per cent) have been described. ${ }^{30}$ Minor side-effects included hoarseness, shivering, perspiration, partial brachial plexus block and stellate ganglion block. ${ }^{30}$ By contrast, there is a very low incidence of cardiovascular complications of CAS with cervical block and, compared with general anaesthesia, a decrease in the incidence of postoperative hypertension and a reduction in the duration of hospital stay have been reported. ${ }^{31,32}$

\section{Clinical recommendations}

Cervical epidural anaesthesia seems to be suitable and effective to perform CAS and to allow sensitive and reliable information on cerebral function to be obtained. Cervical epidural anaesthesia is a simple technique, easy to perform in all circumstances by trained anaesthetists. The incidence of complications is low but side effects such as hypotension and bradycardia occur frequently and require appropriate management. This technique should be considered as an alternative to cervical block for CAS.

\section{References}

1 Conolly JE. Carotid endarterectomy in the awake patient. Am J Surg 1985; 150: 159-5.

2 Peitzman $A B$, Webster $M W$, Loubeau JM, Grundy $B L$, Bahnson $H T$. Carotid endarterctomy under rcgional (conductive) anesthesia. Ann Surg 1982; 196: 59-64.

3 Bause GS. Intertubercular cervical block: a new anesthetic technique. Anesth Analg 1987; 66: S8.

4 Dogliotti AM. Segmental peridural anesthesia. Am J Surg 1933; 20: 107-9.

5 Catchlove $R F H$, Braha $R$. The use of cervical epidural nerve blocks in the management of chronic head and neck pain. Can Anaesth Soc J 1984; 31: 188-91.

6 Green $C D$. Cervical epidural anesthesia for carotid endarterectomy. Surg Gynecol Obstet 1962; 117: 366-7.

7 Cousins MJ, Bromage PR. Epidural neural blockade. In: Cousins MJ, Bridenbaugh PO (Eds.). Neural Blockade. 2nd ed. Philadelphia. JB Lippincott Co. 1988. 266.

8 Mehta $M$. Maher $R$. Injection into the extra arachnoid subdural space. Anaesthesia 1977; 32: 760-3.

9 Cheng PA. The anatomical and clinical aspects of epidural anesthesia. Part 1. Anesth Analg 1963; 42: 398-406.

10 Waldman SD. Complications of cervical epidural nerve blocks with steroids: a prospective study of 790 consecutive blocks. Reg Anesth 1989; 14: 149-51.

11 Rao TKL, El-Etr AA. Anticoagulation following placement of epidural and subarachnoid catheters. Anesthesiology $1981 ; 55$ : 618-20.
12 Odoon JA, Sih IL. Epidural analgesia and anticoagulant therapy. Experience with one thousand cases of continuous epidural. Anaesthesia 1983; 38: 254-9.

13 Dohi $S$, Takeshima $R$, Naito $H$. Ventilatory and circulatory responses to carbon dioxide and high level sympathectomy induced by epidural blockade in awake humans. Anesth Analg 1986; 65: 9-14.

14 Takasaki $M$, Takahashi $T$. Respiratory function during cervical and thoracic extradural analgesia in patients with normal lungs. Br J Anesth 1980; 52: 1271-5.

15 Negre I. Gueneron JP. Ecoffey $C$ et al. Ventilatory response to carbon dioxide after intramuscular and epidural fentanyl. Ancsth Analg 1987; 66: 707-10.

16 Green RM, Messick WJ, Ricotta JJ et al. Benefits, shortcomings, and costs of EEG monitoring. Ann Surg 1985; 201: 785-92.

17 Michenfelder JD, Sundt TM, Fode N, Sharbrough FW. Isoflurane when compared to enflurane and halothane decreases the frequency of cerebral ischemia during carotid endtarerectomy. Anesthesiology 1987; 67: 336-40.

18 Stevens RA, Stanton-Hicks MDA. Subdural injection of local anesthetic: a complication of epidural anesthesia. Anesthesiology 1985; 63: 323 .

19 Knoblanche GE. The incidence and ctiology of phrenic nerve blockade associated with supraclavicular brachial plexus block. Anesth Intensive Care 1979; 7: 346-50.

20 Chauvin $M$, Lebrault $C$, Gauneau $P$, Goeau $O$, Duvaldestin $P$. Effects of bupivacaine cervical epidural blockade on respiratory function. Anesthesiology 1987; 67: A262.

21 Bonnet F, Szekely B, Abhay K, Touboul Ch, Boico O, Saada $M$. Baroreceptor control after cervical epidural anesthesia in patients undergoing carotid antery surgery. $\mathrm{J}$ Cardiovasc Anesth 1989; 3: 418-24.

22 Dohi S, Nisikawa T, Ujike Y, Mayumi T. Circulatory responses to airway stimulation and cervical apidural blockade. Anesthesiology 1982; 57: 359-63.

23 Takeshima R, Dohi $S$. Circulatory responses to baroreflexes, Valsalva maneuver, coughing, swallowing, and nasal stimulation during acute cardiac sympathetomy by epidural blockade in awake humans. Anesthesiology $1985 ; 63,500-8$.

24 Klassen GA, Bramwell RS, Bromage PR et al. Effect of acutc sympathectomy by epidural anesthesia on the canine coronary circulation. Anesthesiology 1980; 52; 8-15.

25 Reiz $S$, Balfors $E$. Coronary hemodynamic effects of general anesthesia and surgery. Reg Anesth 1982; 7 (suppl): S8-S18.

26 Cucchiara RF, Sundt TM, Michenfelder JD. Myocardial infarction in carotid endarterectomy patients anesthetized with halothane, enflurane, or isoflurane. Anesthesiology 1988; 69: 783-4. 
27 Winslow CM, Solomon DH, Chassin MR et al. The appropriateness of carotid endarterectomy. N Engl J Med 1988; 318: 721-7.

28 Shaw DA, Venables GS, Cartlidge NEF et al. Carotid endarterectomy in patients with transient cerebral ischemia. J Neurol Sci 1984; 64: 45-53.

29 Ennix CL Jr, Lawrie GM. Morris GC Jr et al. Improved results of carotid endarterectomy in patients with symptomatic coronary disease: an analysis of 1,546 consecutive carotid operations. Stroke 1981; 10: 122-5.

30 Satyanarayana T, Maghul A, Ramathan S. Tunrdorf $H$. Cervical plexus block for carotid endarterectomy. Anesthesiology 1981; 55: A170.

31 Prough DS, Scuderi P, Stullken E, David CH. Myocardial infarction following regional anaesthesia in patients undergoing carotid endarterectomy. Can Anaesth Soc J 1984; 31: 192-6.

32 Corson JD, Chang BB, Leopold PW et al. Perioperative hypertension in patients undergoing carotid endartercctomy: shorter duration under regional block anesthesia. Circulation 1986; 74: 11-4. 